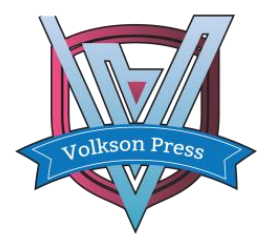

Contents List available at VOLKSON PRESS

Mechanical and Control Engineering (MCE)

DOI : http://doi.org/10.26480/wsmce.01.2017.24.26

\title{
EXPERIMENTAL STUDY ON LOGISTIC DISTRIBUTION OF WHOLE STALK SUGARCANE HARVESTER
}

\author{
Zhonghua Shen*, Bo Huang \\ College of Mechanical and Control Engineering, Guilin University of Technology, Guilin, Guangxi 541004, China \\ *Corresponding Author E-mail: 247525600@qq.com
}

This is an open access article distributed under the Creative Commons Attribution License, which permits unrestricted use, distribution, and reproduction in any medium, provided the original work is properly cited

\section{ARTICLE DETAILS}

\section{Article History:}

Received 02 october 2017 Accepted 06 october 2017 Available online 11 november 2017

Keywords:

\section{ABSTRACT}

The main components of whole stalk sugarcane harvester are divided into these parts: divid system, cutting system, feeding system, stripping system, power system, control system and so on. The blockage of the logistics channel is the bottleneck of restricting the promotion and development of the sugarcane harvester. Through the field investigation and the treatment of feeding roller and output roller, it is indicated that the main form of the blockage of the logistics channel in the process of the harvest of the sugarcane harvester. From harvesting machine own parameter setting, improve jam phenomenon.

Sugarcane harvester, logistics

distribution, jamming,

\begin{tabular}{rr} 
experimental & study \\
\hline
\end{tabular}

\section{Introduction}

The sugarcane harvester generally includes, as shown in Figure 1, several modules such as the cane support system, the cutting table system, the feeding system, the stripping system, the power system and the control system. The logistics channel congestion of sugarcane harvester is a bottleneck problem which restricts the further development of sugarcane harvester.

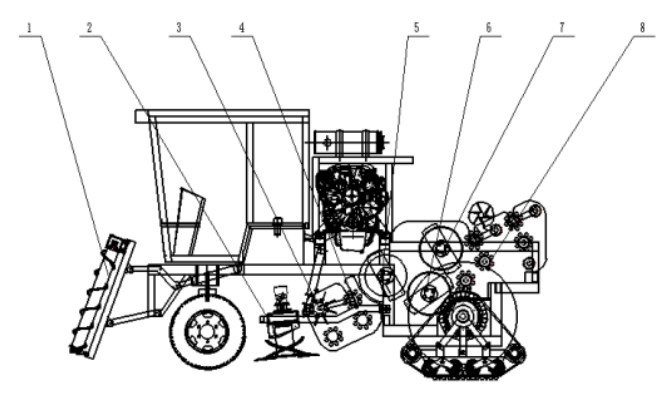

feeding systems, connections between the feeding system and the stripping system, and at the exit of the logistics channel. Through the highspeed photography test of the cutting table mechanism, the stripping mechanism and the logistics outlet, it is centered that the distribution of the logistics can be found.

\subsection{Cutting table mechanism test analysis}

Cutting system is the most important function mechanism, the operation of it can directly affect the coming year of sugarcane output. Because of the special structure of the cutting system, the double rotating cutting causes the sugar cane to concentrate on the middle of the logistics passage [2]. High speed photography captures the image as shown in Figure 2. In the process of cutting, the harvester front right direction clusters (Figure 2 (a) shows) were pushed into a certain angle with the ground by the pressing roll (e.g. Figure 2 (b)), then cut by the double cutter (Figure 2 (c) below). Due to the rotational motion of pressing roller and the double head, the cane gather the central logistics channel (Figure 2 (d) below). A large number of sugarcane in the central distribution are easy to form central congestion.
1 - divided system 2 - cutting system 3, 4 - feeding system 5,6,7 - stripping system 8 - auxiliary transp
system 8 - auxiliary transport system

\section{Figure 1: Structure of whole stalk sugarcane harvester}

In the process of harvesting, due to the mismatch between the conveying speed and the production efficiency, congestion often occurs at the connections between the cutting system and the feeding system, the connections between the feeding system and the stripping system, and at the exit of the logistics channel [1]. As a result, the operation efficiency and harvest quality of the harvester are reduced directly. Experiments show that the logistics congestion is not only caused by the mismatch of efficiency of each organization. The logistics distribution irrationality of the logistics channel is also the direct cause of logistics congestion.

\section{LOGISTICS PROCESS TEST ANALYSIS}

There are 3 main locations in the logistics process which are prone to congestion, respectively, including connections between the cutting and

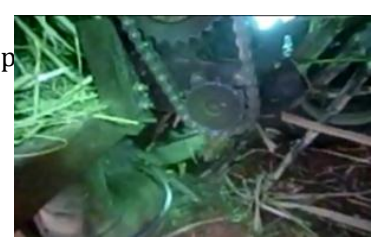

(a) The sugarcane location

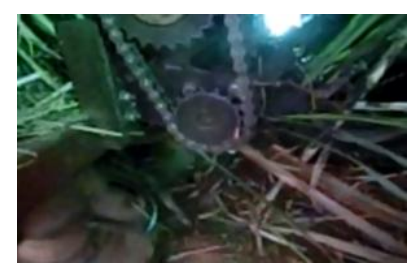

(b)The sugarcane was pressure down 


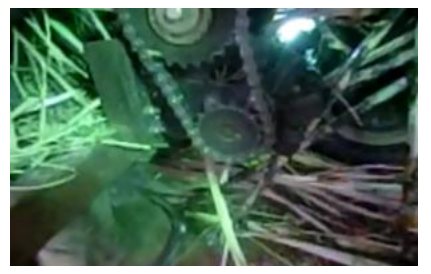

(c)The sugarcane was cut off

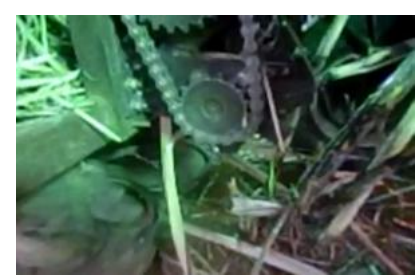

(d) The sugarcane was fed in

Figure 2: Cutting process image

\subsection{Stripping system test analysis}

The stripping system is one of the main functional systems of the sugarcane harvester. The movement state of sugarcane in the stripping system is the key factor that influences impurity rate of the harvester. At the left after the stripping system install high an speed camera, as shown in Figure $3(a, b)$, the sugarcane is mainly located in the middle of the logistics corridor. The leaf brush deformation produces a blessing in the sugarcane. As the leaf roller rotates, the sugar cane is fed into the next body and the leaves of the cane are stripped. When a single sugar cane enters a leaf brush gap, the leaf brush is of type U. But the leaf brush of more canes is of type $\mathrm{V}$ with the decrease of contact area and contact force.

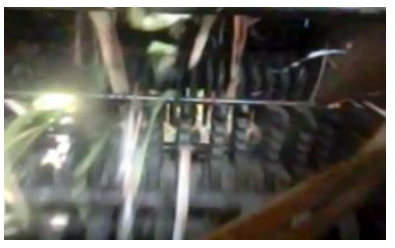

(a)

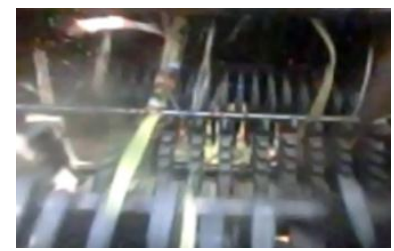

(b)
Figure 3: Image of peeling process

\subsection{Output port test analysis}

Sugarcane harvester's output port is easy to plug. In the field test, the collected photographic material of the output port can also indicate in harvester logistics channel, the congestion is the main "middle block", as shown in figure $4(a, b)$.

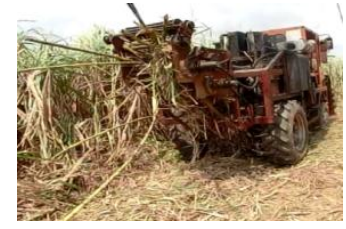

(a)

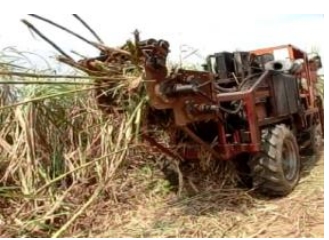

(b)
Figure 4: Image of output port

\section{TEST OF CONVEYOR ROLLERS' ABRASION AND DEFORMATION}

\subsection{Experiment principle}

After the new production of the sugarcane harvester has been put into use, the flexible components installed on each input roll of the logistics channel are used at the same time for the first maintenance. The greater number of sugarcane, the greater the wear of flexible components, and the more parallel sugarcane, the greater the deformation of flexible components. Therefore, observing and collecting the amount of wear and tear of the flexible components on the first maintenance can quantify the distribution law of the sugarcane in the logistics corridor.

\subsection{Experiment method}

It is difficult to measure the wear and deformation of a single flexible component when mounted on a harvester. The outline size of the flexible components will deform two times during the disassembling process, which will affect the result of the experiment. Therefore, in the experiment, circumference of the feeding roller and the output roller, which is easy to be measured, are the target of the test. The feeding roller and the output roller are evenly divided and marked as 30 sampling points, and the circumference of the shaft section of each sampling point is measured 5 times, and the average value can be obtained [3].

\subsection{Experimental result}

The experimental result of conveyor rollers' abrasion and deformation and the measured roll, as shown in Figure $5(\mathrm{a}, \mathrm{b}, \mathrm{c})$,both further show the concentration effect of harvester logistics distribution. The wear and deformation occurred in the middle part of some flexible components can be observed by the naked eye.
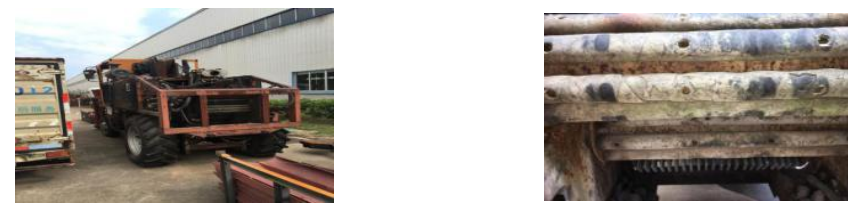

(a)Prototype to be maintained

(b) Image of conveying roller

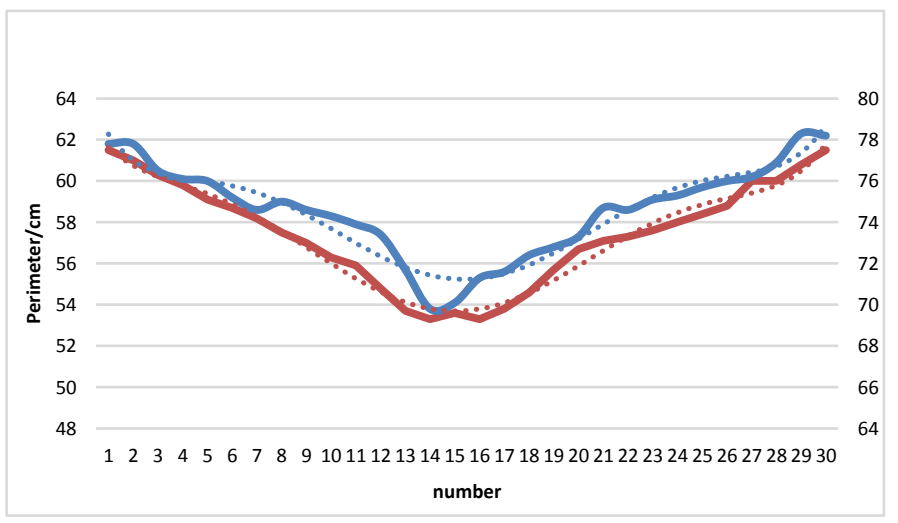

(c) Experimental result

Figure 5: Test samples and results

\section{EFFECT TEST OF CONCENTRATED DISTRIBUTION ON HARVEST QUALITY}

\subsection{Experiment principle}

As observed by previous experiments, when a large number of parallel sugarcane enters the harvester logistics corridor, it is a certain degree of central distribution that the sugarcane would show [4]. The more sugarcane in parallel, the more obvious the degree of centrality. When the efficiency of the front mechanism is greater than the working efficiency of the back mechanism, the degree of centralized distribution of the logistics channel can be controlled.

\subsection{Experiment method}

When the sugarcane harvest machine is finished, the impurity content is taken as the reference standard. The experimental principle is to control the concentration distribution of the logistics by controlling the operation speed of the harvester feeding system and the stripping system [5]. Without changing the structure of the original sugarcane harvester, only changing the parameter setting can improve the centralized distribution [6].

\subsection{Experimental result}

By adjusting the cutting conveying speed, travel speed and advance speed of the sugarcane harvester, the related variables are gradually increased to improve the efficiency of the front part of the mechanism, and the results of each set of data and impurity content are obtained [7,8]. Analysis 
of table 1 shows that to a certain extent, the pretreatment rate of sugarcane harvester is increased, and the blockage rate of harvester is reduced, the work efficiency is improved, and the impurity rate is reduced.

Table 1: Results of preprocessing speed and impurity content of mechanism

\begin{tabular}{|c|c|c|c|c|}
\hline $\begin{array}{l}\text { Serial } \\
\text { number }\end{array}$ & $\begin{array}{l}\text { Cutter speed } \\
(\mathrm{rpm})\end{array}$ & \multicolumn{2}{|l|}{$\begin{array}{l}\text { Conveying } \\
\text { speed }(\mathrm{rpm})\end{array}$} & \multicolumn{2}{|c|}{$\begin{array}{l}\text { Travel } \\
\text { speed }(\mathrm{mm} / \mathrm{s}\end{array}$} & $\begin{array}{l}\text { Impurity } \\
\text { content }\end{array}$ \\
\hline 1 & 550 & 200 & 167 & 3.41 \\
\hline 2 & 650 & 210 & 172 & 1.288 \\
\hline 3 & 750 & 220 & 189 & 0.87 \\
\hline 4 & 850 & 230 & 200 & 0.97 \\
\hline
\end{tabular}

\section{CONCLUSION}

In this paper, the distribution law of distribution logistics of sugarcane harvester was studied by means of high-speed photography and experimental measurement. The effect of physical distribution of sugarcane harvester on harvest quality was discussed. In the actual operation of sugarcane harvester, the logistics distribution is in the middle position, and the more obvious the central tendency is, the lower the harvest quality of the harvester. Proper improvement of the pretreatment rate of sugarcane harvester can reduce the congestion in the middle to a certain extent, improve the working environment of the harvester and increase the harvest rate.

\section{REFERENCES}

[1] Bianchni, A., Magalhaes, P.S.G. 2008. Evaluation of coulters for cutting sugar cane residue in a soil bin. Academic Press Biosystems Engineering, 7, 360-385.

[2] Zhaoxin, L., Gongfan, N. 2014. Principle and application of sugarcane harvesting mechanical structure. Guangxi Sugar Industry, 2 (1), 14-20.

[3] Zhonghua, S., Bo, F. 2016. Experimental study on knockdown and base cutter to the cutting quality of sugarcane stalk. Journal of Chinese Agricultural Mechanization, 37 (9), 62-66. doi: 10.13733/j.jcam.issn.2095-5553.2016.09.014.

[4] Zhonghua, S., Shangping, L. Fanglan, M. 2013. The effect of cutting parameters on cutting quality of small sugarcane harvester. International Agricultural Engineering Journal, 22 (3), 70-77.

[5] Shicheng, Z. 2010. Study on the influence factors of sugarcane cutting. In Nanning, Guangxi University.

[6] Yong, Z., Yinggang, O., Zhaofu, M. 2012. Design and experiment of oblique cutting and feeding device for sugarcane. Transactions of the Chinese Society of Agricultural Engineering, 28 (14), 17-23. doi: 10.3969/j.issn.1002-6819.2012.14.003 